\title{
Empirical Study on Morphological Errors of Mongolian Learners in English Writing
}

\author{
Xiaoli Bao ${ }^{1}$ \\ ${ }^{1}$ School of Foreign Language, Inner Mongolia University for Nationalities, Tongliao, Inner Mongolia, China \\ Correspondence: Xiaoli Bao, Huolinhe Street No. 22, School of Foreign Language, Inner Mongolia University \\ for Nationalities, Tongliao, Inner Mongolia, China. E-mail: nmbaoxiaoli@163.com
}

Received: November 14, 2014 Accepted: December 26, 2014 Online Published: February 25, 2015

doi:10.5539/ells.v5n1p62 URL: http://dx.doi.org/10.5539/ells.v5n1p62

\begin{abstract}
Based on Error Analysis, this article undertakes an empirical study on the Mongolian learners' morphological errors in their English writing and tries to analyze why they make such errors. From analysis, we can make such a conclusion that some of Mongolian students' morphological errors are interlingual which are caused by the interference from Mongolian, and others are intralingual which are caused by over-generalization, ignorance of rule restrictions, incomplete application of rules and false concept hypothesis. The rest are caused by Mongolian students' second language, Chinese. The characteristics of these errors are simple, and primary. As for the interlingual error, teachers should be patient because students will little by little approach to target language with hard work. These errors may eventually disappear. As for the intralingual errors, it happens because Mongolian students haven't laid a solid foundation of English basic knowledge. Therefore, it is significant for Mongolian students to work hard. The author also gives some suggestions on how to improve Mongolian learners' English proficiency.
\end{abstract}

Keywords: morphological errors, Mongolian students, English writing

\section{Introduction}

Teaching English as a foreign language has made rapid progress in China. However most studies on foreign language learning and teaching are related to Han students, the studies on the minority ethnic English learners are not paid much attention to.

It is known that minority ethnic English learners have unique culture and lifestyle that is different from those of Han English learners. Minority ethnic English learners have their mother tongue, this may cause them experience a different process of learning English compared with Han students. Therefore, the research of minority ethnic students' English learning really deserves the particular attention. As is known, writing is considered to be the last acquired skill among four basic skills of language learning. Compared with listening, speaking, reading, writing is the most difficult, but very important, because it can show a person's overall ability in language learning.

There are lots of Mongolian students in Inner Mongolia Autonomous Region who learn English as their foreign language. They feel writing is difficult, they make all kinds of errors. Some errors are universal to all English learners; other errors are caused by their mother tongue, Mongolian language and by their second language, Chinese. Based on Error Analysis, this thesis aims to explore what are the major types of morphological errors made by Mongolian learner in English writing, and what are the possible reasons of these errors.It is hoped that the research results can give some suggestions to English learning and teaching of the Mongolian learners.

\section{Theory}

There are mainly three theories related to Errors Analysis.

\subsection{Contrastive Analysis}

According to Longman Dictionary of Language Teaching and Applied Linguistics, Contrastive Analysis refers to the comparison of linguistic systems of two language, for example the sound system or the grammatical system (Richards, Platt, \& Platt, 2000).

Contrastive Analysis was rooted in the practical need to teach a second language in the most effective way 
possible. Its psychological base is behaviorism and linguistic base is structuralism. The theory was first advanced by Lado (Robort, 1957) when he wrote his famous monograph Linguistics across Cultures. In this book, he claimed that "those elements that are similar to his native language will be simple for him and those elements that are different will be difficult." This conviction that linguistic differences could be used to predict learning difficulty produced the notion of contrastive analysis hypothesis (CAM): "where two languages were similar, positive transfer would occur, where they were different, negative transfer or interference would result." (Larsen-Freeman, 1991, p. 253). Lado also emphasizes the importance of comparison between the second language and the native language in terms of teaching. He holds that the teacher who has made a contrast of the foreign language with the native language of the students will know better what the real problems are and can provide for teaching them." (Lado, 1957, p. 102) Contrastive analysis theory also has a certain guiding significance to today's English teaching in our country. It can help foreign language teachers to understand and predict what kinds of errors students may make in their English learning so as to nip in the bud.

But with the deepening of the research on foreign language teaching, in the late $1960 \mathrm{~s}$ and early 1970s, people found that there are many other factors that affect language learners to study foreign language besides mother tongue interference. The emphasis of contrastive analysis is to predict the difficulty and errors, but it is proved that many errors can't be discovered by contrastive analysis. Contrastive analysis focuses solely on the external environment of the language, ignoring the language learners themselves. It exaggerates the role of the language transfer. Neither does it put the learners into the proper place, nor does it fully consider the complexity of language itself. In addition to that, the attitude of contrastive analysis towards errors is wrong. Contrastive analysis holds belief that errors are not tolerable. As a result, more and more people began to realize the limitations of comparative analysis.

Moreover, in the process of foreign language learning, there are many reasons for the errors. Statistical data also proves that the suspect is not unreasonable. In order to research what causes the errors, people conduct a comprehensive in-depth study on errors. People begin to transfer the emphasis of research to the language learning process itself. So, in the 1970s, a new analysis of error in foreign language learning was born, it is error analysis.

\subsection{Error Analysis}

Error Analysis was popular in 1970s and become an important method to research second language acquisition. Corder was the pioneer of the modern error analysis, and in his article The Significance of Learners' Error, Corder (1967) points out "people can't only see error as a thing that should be eradicated. Error itself also has significance to the learning process. Corder (1971) points out "Making errors is inevitable and is a necessary part of learning process." Error Analysis constitutes the first serious attempt to investigate learners' language in order to discover how learners acquire a second language. Corder notes that errorsare significant in three ways: they provide the teacher with information about how much the learner have learned, they provide the researcher with evidence of how language is learnt, and they serve as devices by which the learners discover the rules of the target language. Corder (1974) suggests that EA research have five steps: error collecting; error identification; error classification; error explanation; error evaluation.

According to Corder (1981), EA is a type of bilingual comparison which is between the leaners' first language and the target language. James (2001) claims that "Error Analysis involves first independently or objectively describing the learners' interlanguage and target language itself, followed by a comparison of the two, so as to locate mismatches"

The psychological basis of Error Analysis is cognitive theory which is related to Chomsky's language acquisition and universal grammar. Therefore, it's a methodology for describing second language learners' language system. Error Analysis is recognized as an essential branch of applied linguistics and constitutes the appropriate start for Second Language Acquisition.

However, any theory has its limitation. The limitation of Error Analysis can be concluded as followings: Firstly, EA just focus on errors, while ignores the whole process of language learning. Secondly, the researchers only study the reasons of learners' errors, but not successful parts. Thirdly, there is no consistent standard for the definitions and classifications of error. Besides, EA is difficult to account for all the areas of the target language in which learners have difficulty. In terms of these limitations, Interlanguage occurred.

\subsection{Interlanguage}

Interlanguage is a language between mother tongue and target language system, also known as "transition" or "Interlanguage". It means that in the process of second language acquisition, based on the input of target 
language, language learners through certain learning strategies formdynamic language system that is both different from their mother language and from the target language. This dynamic language system will gradually be transferred into target language. Interlanguage Theory was first put forward by Selinker etc. in the late 1960s. Selinker put forward the concept of hypothesis of interlanguage in 1969 and wrote it into his famous paper "interlanguage". Its inherent assumptions are as follows: the starting point of interlanguage is the learners' native language. With increasing accumulation of the knowledge, interlanguage gradually closes to the target language in the process of learning. This is just what the leaners need. The process of foreign language learning is just the process of constant adjustment in order to approach the target language. (Selinker, 1972)

\section{Method}

\subsection{Research Questions}

This research aims to investigate how Mongolianinfluences on Mongolian students' English learning. This thesis will try to answer the following questions:

1) What are the main types of morphological errors that can be found in Mongolian students' English writing?

2) What causes Mongolian students make such morphological errors?

3) What are the implications of these morphological errorsto the English teaching?

\subsection{Subjects}

There are 50 Mongolian majors take part in this study. They are from School of Foreign Language in Inner Mongolian University for Nationalities. They come from different grades, including freshmen, sophomore, the third year students and the senior students.

All these students have studied English in their middle school. But because English score only account for a small proportion in the College Entrance Examination, English was not paid much attention to in the period of their middle school, which causes the situation that Mongolian students' English level is far behind that of Han students. All of the subjects bilingual, they can speak both Mongolian and Chinese. That is to say, Mongolian is their mother language, Chinese is their second language and English is their foreign language.

\subsection{Instruments}

There are three kinds of instruments in this study: the students' writing assignment, questionnaire, and interview.

Each subject was assigned two formal writing and on journal in order to see what kinds morphologicalerrors Mongolian students make. The formal writing assignments were examined carefully so as to avoid accidental mistakes. Students' journal may reflect some underlying truth of Mongolian students' English learning. Questionnaires and interviews were conducted in order to provide more information for the analysis.

\subsection{Procedures}

Firstly, determine the subjects. 50 students are chosen from four different grades in School of Foreign Language in Inner Mongolia University for Nationalities.

Secondly, carry out Questionnaire Survey. All the 50 subjects were given enough time to finish questionnaire to make sure of getting authentic and useful information.

Thirdly, collect data. For each subject, two formal writing assignments and one journal were gathered for analysis.

Fourthly, identify the errors. The author went over the writing pieces carefully and identifiedeach error sentence on morphology and when could not decide whether a sentence is correct or wrong, the author went to foreign teachers or professors for help.

Fifthly, interview subjects. Ten of fifty subjects were interviewed. Interview provides more information for error analysis.

Sixthly, describe and explain the errors. Mongolian students' morphological errors in writing are divided into eight partsand the possible causes are explored to find out whether they are interlingual or intralingual.

Seventhly, evaluate the errors. The author puts forward right attitudes towards morphological errorsmade by Mongolian students and also gives some implications and suggestions on English learning and teaching.

\section{Discussion}

In this part, the author will describe and explain the morphological errorsmade by Mongolian students in writing.

There are totally 1229 errors in the writing samples, excluding errors on spelling. The number of spelling errors 
is not taken into consideration.

The morphological errorsin Mongolian students' writing samples are stated from these aspects: verb, noun, adjective, adverb, pronoun, preposition, article, etc.

\subsection{Verb}

The number of errors connected with the use of verbs is 180 , which accounts for 14.65 percent of the total number. Distribution of errors in this category is indicated in table 1.

Table 1. Errors related to verbs

\begin{tabular}{lll}
\hline Category & Example & Number \\
\hline Tense & I am going to supermarket when my friend rang me up. & 41 \\
& I learned English since 1990. & \\
& I go to Beijing last month. & 13 \\
\hline Voice & $\begin{array}{l}\text { People are not allow to smoke in public places. } \\
\text { My bike stolen last week. }\end{array}$ & 12 \\
\hline Auxiliary verbs & DoLily have brown hair? & 19 \\
& It don't mean that I am not willing to help you. & \\
\hline Modal Verbs & I can to do my homework on my own. \\
& I would walking for a while after supper. & 38 \\
\hline Vi. and Vt. & He talked Mr. Wang just now. & 57 \\
\hline V-ing & He didn't ask reward. & \\
\hline
\end{tabular}

From the table, we know that 41 students make errors on use "tense". It shows that Mongolian students do not have a good command of grammar "tense". For example, how to use present perfect tense? "I learned English since 1990" should be corrected in this way: I have learned English since 1990". When "since" indicates for a period of time, the tense in the main clause or sentence should be "present perfect tense". "I go to Beijing last month" should be changed to "I went to Beijing last month" because "last month" is obviously the adverbial of time of the past simple tense.As far as voice concerned, when subject and predicative verb is passive relationship, passive voice should be used. So "My bike stolen last week" should be changed to "My bike was stolen last week."

Why do Mongolian students make such kinds of errors? Are they influenced by their mother tongue language? Obviously not. In Mongolian language, there also exist verb tense. Different verb forms are used to indicate actions in the past, at present, or in the future. Verbs also have active voice and passive voice and verbs are also divided into transitive verbs and intransitive verbs.As for the errors in V-ing, a preposition is often followed by "doing" instead of "do". In Mongolian language, there is not such a category words as prepositions. Verbs just modify their forms with the changing of cases, tenses and voices.

From the above analysis, we know that the errors in this grammatical category of "verb" all belong to the intralingual errors.

\subsection{Noun}

The number of errors related to nouns is 130 , which accounts for 10.58 percent of the total number of errors. Pay attention to Table 2 .

Table 2. Errors related to nouns

\begin{tabular}{lll}
\hline Category & Example & Number \\
\hline Numerals before nouns & There are two bird singing in the tree. & 33 \\
& Four student take part in this game. & \\
\hline No numerals before nouns & I'd like to watch some interesting TV program. & 97 \\
& They are in the same school, but they are in different grade. & \\
\hline
\end{tabular}

Comparatively Mongolian students make large amount of this kind of errors.Mongolian students often make this kind of errors. Therefore, it needs to be explored carefully.

In Mongolian language, there are countable noun and uncountable. They have different usages. Countable nouns 
have both singular form and plural forms. The plural form is formed by adding certain suffixes to the corresponding singular form. However, according to the rules of Mongolian language, when there is a numeral in front of a noun, the noun should use its singular form instead of the plural form. This can be used to explain why Mongolians students make such errors as "four student", "two bird" etc. From above explanation, we know this kind of errors can be classified into the interlingual errors. The 96 errors in the second group shouldn't ascribe to first language interference, because they are caused by students carelessness.

\subsection{Preposition}

The number of errors connected with the use of preposition is 108 , which accounts for 8.79 percent of the total number. Statistic data of errors are given in table 3.

Table 3. Errors related to prepositions

\begin{tabular}{lll}
\hline Category & Example & Number \\
\hline Omission & $\begin{array}{l}\text { I am looking forward (to) the letter from my pen pal. } \\
\text { The fish swims out (of) the water. }\end{array}$ & 30 \\
\hline Addition & $\begin{array}{l}\text { If you are interested in, you can have a try. } \\
\text { The population has increased by from 1,800 to 2,000 }\end{array}$ & 9 \\
\hline Wrong use & $\begin{array}{l}\text { I bought the pen to you as it is your birthday today. } \\
\text { I have faith for him. }\end{array}$ \\
\hline
\end{tabular}

The number of this kind of errors is not small. So it cannot be neglected. Why do Mongolian students make such kind of errors? We know that in Mongolian language, there are not such words that function as prepositions in English. Mongolian learners cannot transfer the rules in their mother tongue into their English learning. Therefore, these errors should be grouped into intralingual errorsthat are caused by poor command of English. As is known, in English, prepositions play a very important role. Though prepositions are small in number, they frequently occur in sentences. Thus, Mongolian students should spend more time on the learning of English prepositions.

\subsection{Article}

The number of error on the use of article is 101, which accounts for 8.22 percent of the total errors. These errors are furthered grouped into four sub-categories, which are shown in the table 4.

Table 4. Errors concerning articles

\begin{tabular}{lll}
\hline Category & Example & Number \\
\hline Omission & I paid (a) visit to my grandma yesterday. & 40 \\
& When I studied in (the) university, I had the habit of reading aloud. & \\
\hline Addition & What does a happiness mean? & 31 \\
& He has made a rapid progress in his English study. & \\
& It is the time for time to do morning exercises. & 7 \\
\hline Wrong use of "a" and "an" & He is a honest boy. & 23 \\
\hline Wrong use of "a(an)"and "the" & He studied in an university which is not well-known. & \\
& I have a cat. A cat is very cute. I love it very much. & \\
\hline
\end{tabular}

Definite article and indefinite article are difficult to learn for any English learners, including Mongolian students. There exist no articles both in Chinese and Mongolian language. From the questionnaire we know that most Mongolian students find it hard to use article properly.This kind of errors belongs to intralingual error that is difficult to deal with. Teachers should make every effort to let Mongolian students know how to use the articles appropriately.

\subsection{Pronoun}

The number of errors related to pronouns is 40 , which accounts for 3.25 percent of the total number. See table 5 . 
Table 5. Error concerning pronoun

\begin{tabular}{lll}
\hline Category & Example & Number \\
\hline Personal pronoun & There is something wrong with she. & 13 \\
& They found their had lost the way. & 18 \\
\hline Demonstrative pronoun & I'll continue doing like this (that) for my good health. & So it (that) is why people say seeing is believing. \\
& There (It) is raining outside. & 5 \\
\hline Possessive pronoun & You brother is handsome. \\
\hline Indefinite pronoun & You should take good care of you father. \\
& Would you like anything to drink? & 4 \\
\hline
\end{tabular}

Why do Mongolian students make such errors? The author believes that the error like "you brother" and "you baby" are caused by second language interference. Some Mongolian students are affected by Chinese language“你弟弟”or “你爸爸” and they translate the phrases “word by word".

\subsection{Adverb}

The number of errors related to adverbs is 33, which takes up 2.69 percent of the total number. Errors of this kind are mainly connected with the position of adverbs in a sentence. Pay attention to table 6 .

Table 6. Errors concerning adverb

\begin{tabular}{lll}
\hline Category & Example & Number \\
\hline Adverb+verb & My brother hard study to pass the College Entrance Examination. & 33 \\
& They right away realized that they missed the last bus home. & \\
& My brother just can play computer games at home on weekend. & \\
\hline
\end{tabular}

What causes students make these errors? The author thinks that some are caused by Mongolian students'mother tongue and other are caused by Mongolian students' second language (Chinese).

The position of adverbs in English is flexible while the position of adverbs in Mongolian is fixed. In Mongolian, adverbs can only appear right before words (verbs or adjectives) they are modifying. No elements are allowed to be inserted between adverbs and verbsladjectives. Actually, one prominent feature of the syntax of Mongolian language is that verbs always appear at the end of the sentences, therefore, no words, except interjections, can appear after verbs. However in English, according to rules some adverbs can only be placed after verbs. This is why the errors occur.

The wrong sentences like "In order to pass the College Entrance Examination my brother hard study" also have something to do with Chinese language, because this wrong sentence is the one that is directly translated from Chinese“为了通过大学入学试我弟弟努力学习.”

\subsection{Adjective}

Errors on use of adjective are connected with comparative degree of adjectives. Error statistics is shown in Table 7.

Table 7. Errors concerning adjective

\begin{tabular}{lll}
\hline Category & Example & Number \\
\hline Comparative degree & She is more taller than me & 17 \\
& My bike is much more newer than his. & \\
\hline
\end{tabular}

The errors concerning the use of adjective are 17, which take up 1.38 percent, much smaller than other categories. Why? The reason is that formation of comparative degree in English and Mongolian language is rather similar. In Mongolian language, several suffixes can be added to the root to form the comparative degree. This similarity brings about a positive transfer from their mother tongue to the target language. Thus, these errors are due to students' poor command of English grammar. These errors are intraligual errors.

\subsection{Part of Speech}

The number of errors concerning part of speech is 83 , which takes up 6.75 percent of the total number of errors. 
Mongolian student often misuse the word class. Look at Table 8

Table 8. Errors concerning part of speech

\begin{tabular}{lll}
\hline Category & Example & Number \\
\hline Misuse of adj. and adv. & He runs slow. & 13 \\
& He can't live independent. & 43 \\
\hline Misuse of adj. and $\mathrm{n}$. & $\begin{array}{l}\text { Do morning exercise is a good way to keep health. } \\
\text { With the development of economic,... }\end{array}$ & 4 \\
\hline Misuse of adv. and v & He often back home late. & 4 \\
\hline Misuse of Prep. and v. & Lin Lin is a good boy. He always helps elderly across the street. & 19 \\
\hline Misuse of $\mathrm{n}$. and v. & With the developing of the society, all of people in China have accessed to computer. \\
& Just as the old say “one apple a day, the doctor away”. & \\
\hline
\end{tabular}

\section{Conclusion}

From the above explanation, we know some Mongolian students' morphological errors are interlingual which is caused by the interference from Mongolian, others are intralingual which is caused by over-generalization, ignorance of rule restrictions, incomplete application of rules and false concept hypothesis and the rest are caused by their second language, Chinese. The characteristics of these errors are simple, and primary.

What attitudes teachers should hold towards these errors? First, teachers should tolerate to students' errors. Interlanguage is developmental. By consistently making hypotheses about the target language, the learner is approaching higher learning stage of the target language, and in this process, the learner modifies some of his or her former hypotheses and some errors may disappear naturally.

What are the implications of errors to the English teaching? Firstly, teachers should help students lay a solid foundation of English. The Mongolian students usually make some simple and "silly" mistakes because they don't have a solid foundation of the English grammar. Teachers should encourage them study hard and lay a solid foundation of English basic knowledge.Secondly, teachers should give students instructions on character, that is to say, students should have such characters as confidence and hard-work, as is shown in Hyde School Principle: "if you teach students the merit of such values as truth, courage, integrity, leadership, curiosity and concern, then academic achievement naturally follows." The teachers should also let the students know the importance of learning strategies. Thirdly, there are similarities between Mongolian and English and teachers can make use of positive transfer to improve students' English learning. Lastly, curricular, syllabus, and textbook that are particular for Mongolian learners should be produced. However it is a difficult task. It needs furthering researching.

What are the limitations of this research? The author only explored the Mongolian students' errors on morphology in writing, it's not enough. The further study should focus on syntax and semantics.

\section{Acknowledgments}

I am extremely grateful to 50 Mongolian majors who take part in this study. They are from School of Foreign Language in Inner Mongolian University for Nationalities. Because of their support and cooperation, I finish this study.

\section{References}

Corder, S. P. (1967). The Significance of Learners' errors. International Review of Applied Linguistics, (5), 161-170. http://dx.doi.org/10.1515/iral.1967.5.1-4.161

Corder, S. P. (1971). Idiosyncratic dialects and error analysis. International Review of Applied Linguistics, (9), 147-159. http://dx.doi.org/10.1515/iral.1971.9.2.147

Corder, S. P. (1974). Error Analysis. London: Oxford University Press.

Corder, S. P. (1981). Errors analysis and interlanguage. Oxford: Oxford University Press.

James, C. (2001). Errors in language learning and use: exploring error analysis. Beijing: Foreign Language Teaching and Research Press.

Lado, R. (1957). Linguistics across Culture. Ann Arbor: University of Michigan Press.

Larsen-Freeman, L. (1991). An Introduction to Second Language Acquisition. Longman. 
Richards, J. C., Platt, J., \& Platt, H. (2000). Longman Dictionary of Language Teaching and Applied Linguistics. Beijing: Foreign Language Teaching and Research Press.

Selinker, L. (1972). Interlanguage. International Review of Applied Linguistics.

\section{Copyrights}

Copyright for this article is retained by the author(s), with first publication rights granted to the journal.

This is an open-access article distributed under the terms and conditions of the Creative Commons Attribution license (http://creativecommons.org/licenses/by/3.0/). 